\title{
BMJ Open Does n-3 LCPUFA supplementation during pregnancy increase the IQ of children at school age? Follow-up of a randomised controlled trial
}

\author{
Jacqueline F Gould, ${ }^{1,2}$ Karli Treyvaud, ${ }^{3}$ Lisa N Yelland,,${ }^{1,4}$ Peter J Anderson, ${ }^{3}$ \\ Lisa G Smithers, ${ }^{4}$ Robert A Gibson, ${ }^{5}$ Andrew J McPhee, ${ }^{6}$ Maria Makrides ${ }^{1,2}$
}

To cite: Gould JF,

Treyvaud K, Yelland LN, et al. Does n-3 LCPUFA

supplementation during pregnancy increase the $I Q$ of children at school age? Follow-up of a randomised controlled trial. BMJ Open 2016;6:e011465.

doi:10.1136/bmjopen-2016011465

- Prepublication history for this paper is available online. To view these files please visit the journal online (http://dx.doi.org/10.1136/ bmjopen-2016-011465).

Received 11 February 2016 Revised 24 March 2016 Accepted 5 April 2016

CrossMark

For numbered affiliations see end of article.

Correspondence to Dr Maria Makrides; maria.makrides@sa.gov.au

\section{ABSTRACT}

Introduction: Despite recommendations that pregnant women increase their docosahexaenoic acid (DHA) intake to support fetal brain development, a recent systematic review found a lack of high-quality data to support the long-term effects of DHA supplementation on children's neurodevelopment.

Methods and analysis: We will assess child neurodevelopment at 7 years of age in follow-up of a multicentre double-blind randomised controlled trial of DHA supplementation in pregnancy. In 2010-2012, $\mathrm{n}=2399$ Australian women with a singleton pregnancy $<21$ weeks' gestation were randomised to receive 3 capsules daily containing a total dose of $800 \mathrm{mg} \mathrm{DHA} /$ day or a vegetable oil placebo until birth. $\mathrm{N}=726$ children from Adelaide (all $n=97$ born preterm, random sample of $\mathrm{n}=630$ born at term) were selected for neurodevelopmental follow-up and $n=638$ ( preterm $\mathrm{n}=85$ ) are still enrolled at 7 years of age. At the 7-year follow-up, a psychologist will assess the primary outcome, IQ, with the Wechsler Abbreviated Scale of Intelligence, Second Edition. Specific measures of executive functioning (Fruit Stroop and the Rey Complex Figure), attention (Test of Everyday Attention for Children), memory and learning (Rey Auditory Verbal Learning Test), language (Clinical Evaluation of Language Fundamentals, Fourth Edition) and basic educational skills (Wide Range Achievement Test, Fourth Edition) will also be administered. Caregivers will be asked to complete questionnaires measuring behaviour and executive functioning. Families, clinicians and research personnel are blinded to group assignment with the exception of families who requested unblinding prior to the follow-up. All analyses will be conducted according to the intention-to-treat principal.

Ethics and dissemination: All procedures will be approved by the relevant institutional ethics committees prior to start of the study. The results of this study will be disseminated in peer-reviewed journal publications and academic presentations.

Trial registration numbers: ACTRN12605000569606 and ACTRN12614000770662.

\section{INTRODUCTION}

The omega-3 long-chain polyunsaturated fatty acid, docosahexaenoic acid (DHA, 22:6
Strengths and limitations of this study

- This follow-up study builds on a well-powered and well-conducted randomised controlled trial.

- This follow-up of the DOMInO trial will be one of only four randomised controlled trials to explore the effects of prenatal docosahexaenoic acid (DHA) supplements on child development beyond the age of 3 years.

- A comprehensive range of neurological domains are measured in this follow-up.

- Given the high usage of prenatal supplements containing DHA internationally, this is likely one of the last opportunities for a large trial to compare a DHA intervention with a placebo.

- No planned adjustments for multiple comparisons may be a limitation.

n-3), is a crucial nutrient for the developing brain. It is known to be involved in neurogenesis, signal transduction and neurotransmission. ${ }^{1}$ During pregnancy, DHA is transferred across the placenta to the fetus in high amounts, ${ }^{2}$ where it accumulates in developing neural tissues, particularly during the fetal brain growth spurt in the last trimester of pregnancy. ${ }^{3}$ The frontal areas of the brain are a primary area of DHA accretion and undergo rapid growth at this time. This area of the brain, specifically the frontal cortex, is important for language, memory and higher order cognitive functioning, including purposeful, goal-directed behaviours which are often referred to as executive functions. ${ }^{4}$ The importance of adequate DHA during this key period of brain development is indicated in studies of preterm infants who are denied the full gestation period to accumulate DHA. Infants who are born preterm have lower concentrations of DHA in brain tissues ${ }^{2}$ and are at increased risk of developmental delay, ${ }^{5}$ impaired executive functioning, ${ }^{6}$ attention problems ${ }^{7}$ and 
attention deficit/hyperactivity disorder ${ }^{8}$ compared with their term-born counterparts.

\section{Prenatal DHA intake and child development: evidence from cohort studies}

A supply of DHA in the diet is considered important during pregnancy, with fish being the richest source of DHA. The most compelling data linking maternal DHA intake from fish and seafood during pregnancy with childhood IQ comes from a well-conducted cohort study of 5449 mother-child pairs from the Avon Longitudinal Study of Pregnancy and Childhood. ${ }^{9}$ Fish and seafood intake above the level recommended for pregnancy by the US government was associated with a decreased risk of being in the lowest quartile for verbal IQ and suboptimum prosocial behaviour, fine motor, communication and social development scores at 8 years of age. ${ }^{9}$ These findings are supported by other smaller cohort studies reporting that seafood intake in pregnancy is associated with developmental benefits in childhood such as advanced motor development, social development ${ }^{10} 11$ and language skills at 18 months, ${ }^{10}$ higher receptive vocabulary at 3 years, ${ }^{12}$ higher IQ, language and motor development scores at 4 years, ${ }^{13}$ and reduced hyperactivity, as well as higher verbal IQ at 9 years. ${ }^{14}$ Similarly, cohort studies in which blood DHA concentrations were measured at the end of pregnancy reported associations between higher DHA status and improved attention, and reduced distractibility in infants from birth to 18 months, ${ }^{15} 16$ and better motor development and fewer internalising behaviour problems in children at 7 years of age. ${ }^{17}$ Although these epidemiological studies controlled for numerous confounding factors, there is always the possibility that residual or unknown confounding influenced the results. ${ }^{18}$ Thus randomised controlled trials (RCTs) are essential to establish the extent of benefit of gestational DHA supply on cognition in childhood.

\section{RCTs of maternal DHA supplementation and child development}

There are 11 RCTs investigating the effect of prenatal DHA supplementation on childhood cognitive outcomes that are published or are awaiting publication. ${ }^{16} 17$ 19-33 However, the majority of these studies have limitations that potentially influenced their results. Most studies did not clearly report, or did not have adequate processes to independently generate the randomisation sequence, or to conceal the random allocation, increasing the risk of selection bias. $^{34}$ Furthermore, all studies suffer high attrition (between 27\% and 86\%), ${ }^{15} \quad 16 \quad 19-27 \quad 33$ compounding the fact that many trials were relatively small and therefore underpowered to detect clinically meaningful differences in cognitive outcomes from the beginning. ${ }^{15} 1619-273233$ Other potential biases include systematic postrandomisation losses such as greater attrition from the DHA-supplemented group compared with the control group, ${ }^{19}{ }^{20}$ or postrandomisation exclusion criteria $^{19} 202427$ and possible publication bias where results from completed trials are not published in full. $^{25}{ }^{29}$ One trial modified the eligibility criteria to include participants taking prenatal supplements containing low-dose DHA (up to $200 \mathrm{mg} /$ day) after the trial had started because the high use of supplements was causing recruitment problems. ${ }^{28}$

Given the variation in trial quality, it is not surprising that the results of RCTs investigating the effect of DHA supplementation during that last half of pregnancy on measures of child neurodevelopment have been mixed and largely demonstrated no effect of supplementation. ${ }^{34}$ For example, of the nine trials in which development quotient $(\mathrm{DQ})$ or IQ were assessed, six reported no effect of DHA supplementation on DQ or IQ at $10,{ }^{22}$ $12,{ }^{32} 18$ months, ${ }^{27} 30312.5,{ }^{26} 6.5,{ }^{24} 7^{20}$ or 12 years of age, ${ }^{33}$ although positive effects of DHA supplementation are reported by four trials on one subtest of a DQ assessment at 18 months, ${ }^{31} 2.5^{26}$ and 4 years of age, ${ }^{29}$ as well as the DQ score at 4 years of age ${ }^{19}$ Most trials assessed too few children (15-125 per group) and did not have the statistical power to detect the sort of differences that might realistically be expected between groups as a result of DHA supplementation. ${ }^{34}$

\section{The DOMInO trial}

Our DHA to Optimise Mother Infant Outcome (DOMInO RCT; trial registration \#12605000569606 at http://www.anzctr.org.au) was designed to evaluate the effects of a substantial dose of DHA during the second half of pregnancy on symptoms of postnatal depression to 6 months postpartum and infant cognitive development at 18 months of age. ${ }^{35}$ Women were eligible if they had a singleton pregnancy <21 weeks' gestation and were able to give informed consent. Women were excluded if there was a known fetal abnormality, a bleeding disorder, a history of drug or alcohol abuse, or English was not spoken in the home (as children undergoing developmental testing were required to understand and take instructions from a psychologist in English). At study entry, women were randomly assigned to receive either a fish oil concentrate $(800 \mathrm{mg}$ DHA/ day) or a blend of vegetable oils (no DHA) in capsules that were identical in appearance from $\sim 20$ weeks' gestation until birth. The DOMInO trial is the largest RCT of maternal DHA supplementation in pregnancy with $\mathrm{n}=2399$ women enrolled around Australia.

Outcomes at 18 months: The primary neurodevelopmental outcome was the cognitive scale of the Bayley Scales of Infant Development, Third Edition (Bayley-III) at 18 months of age in a subset of $n=726$ children (powered to detect a clinically meaningful (four-point) difference in development). The neurodevelopment cohort subset consisted of all preterm children and a random sample of term-born children whose mothers were recruited from Adelaide. Secondary outcomes included Bayley-III language and motor scales, as well as developmental delay. We assessed 694 of the 726 
(95.6\%) infants selected for the neurodevelopment cohort. We found no significant difference between groups in the mean cognitive scores of children whose mothers were assigned to receive DHA supplements compared with those assigned to receive placebo (101.8 \pm 11.1 vs $101.8 \pm 12.6$ ), although fewer children from the DHA group had scores indicative of mildly delayed cognitive development (DQ<85, 2.7\% vs $6.6 \%$, RR 0.41, $95 \%$ CI 0.22 to $0.78, \mathrm{p}=0.007){ }^{35}$ These data are consistent with the Avon Longitudinal Study of Pregnancy and Childhood finding ${ }^{9}$ and provide evidence that DHA supplementation is effective at preventing developmental delay in early childhood. Mean language and motor scores did not differ between the groups, although there was a surprising treatment by sex interaction for the language and adaptive behaviour outcomes, which indicated that girls and boys responded differently to DHA treatment. ${ }^{35}$

In addition to the 18-month follow-up, a side study assessed early emergence of executive functioning in a nested side study $(\mathrm{n}=185)$ of term-born DOMInO children. ${ }^{36}$ The measures used were specialised to detect differences in the early development of the executive functioning skills attention, working memory and inhibitory control. We found no significant group differences. ${ }^{36}$

Outcomes at 4 years: To further explore the differences found at 18 months, we assessed neurodevelopment again at 4 years with $\mathrm{n}=646$ (92\% of the 726 children in the neurodevelopment cohort) consenting to an assessment with a psychologist (trial registration $\# 12611001125910$ at http://www.anzctr.org.au). ${ }^{37}$ The primary outcome was DQ as assessed by the Differential Ability Scales, Second Edition. Secondary outcomes were general language ability measured with the Clinical Evaluation of Language Fundamentals (CELF)-Preschool, Second Edition, inhibitory control measured with the efficiency score of the Day-Night Stroop, and short-term memory measured with the Recognition of Pictures and Recall of Digits Forward tests from the Differential Ability Scales. Parents completed the Strengths and Difficulties Questionnaire (SDQ) and the Behaviour Rating Inventory of Executive Function (BRIEF)-Preschool and provided information regarding family demographics, the child's dietary intake of DHA-rich foods, such as fish, eggs, DHA-enriched breads and yogurts, use of DHA supplements, parent-reported medical diagnosis of attention deficit hyperactivity disorder (ADHD), autism and behavioural or learning disorders of children, as well as the home environment (Home Screening Questionnaire (HSQ)), ${ }^{38}$ life events (the Recent Life Events (RLE)), ${ }^{39}$ and family functioning (the Family Assessment Device $(\mathrm{FAD})) .{ }^{40}$ As at 18 months, we found no significant mean group difference in general cognitive functioning of children whose mothers were assigned to receive DHA supplements compared with those assigned to receive placebo at 4 years (DHA group $\mathrm{DQ}=99.6$, 95\%
CI 98.4 to 100.8 vs control group $\mathrm{DQ}=99.4$, $95 \%$ CI 98.3 to 100.6$).{ }^{25}$ We also found that there was no longer a group difference in cognitive delay, and no sex by treatment interactions, although children from the DHA group had slightly poorer scores on the parentcompleted measures of behaviour and executive functioning than control group children, indicating increased parent-perceived problems in the DHA group. $^{37}$

\section{Rationale for the current follow-up}

We propose to conduct a neurodevelopmental assessment focused primarily on cognitive functioning at 7 years of age in the DOMInO neurodevelopment cohort. While the previous assessment at 4 years for these children provided an indication of neurodevelopment in the preschool years and school readiness, new skills develop with age, and as a result, long-term effects on cognitive functioning and deficits that emerge in later years need to be examined.

Cognitive skills develop rapidly during early childhood, ${ }^{41}$ and by age 7 years most cognitive domains can be reliably assessed using valid and standardised instruments. ${ }^{42}$ Importantly, a measure of IQ at 7 years of age is predictive of adult IQ and adult attained education and occupation, ${ }^{43}$ occupational status, material wellbeing, ${ }^{44}$ and mortality risk. ${ }^{45}$ Although an assessment after 7 years of age will also provide a predictive measure of adulthood IQ there is a greater chance of loss to follow-up as the children get older. Assessment at age 7 provides us with the best compromise between an assessment of cognitive function that is predictive of adult functioning with maximal follow-up and the lowest risk of attrition. The suite of developmental assessments at early, middle and late (18 months, 4 and 7 years) childhood is complementary and will provide a more complete picture of the effect of DHA supplementation in pregnancy on children's developmental trajectory during early-mid childhood. Follow-up at 7 years is vital to complete the picture and provide the long-term outcome data necessary to indicate the permanency of any effects of prenatal DHA supplementation. Furthermore, given the information relating to previous trial quality and low power, the methodologically robust and well-powered DOMInO RCT is expected to provide robust data regarding the effect of DHA supplementation in pregnancy on long-term cognitive development of children. ${ }^{34}$

\section{Aims and hypothesis}

Our aim is to determine whether DHA supplementation during pregnancy enhances cognitive function at 7 years of age, with our primary outcome being IQ. The areas of the brain thought to be most susceptible to DHA exposure in the last trimester of pregnancy when our intervention took place are the frontal lobes. These lobes undergo two critical periods of development during childhood. We expect that the hypothesised 
benefits of prenatal DHA supplementation on the performance of these lobes will be detectable following these key development periods. ${ }^{4}$ We hypothesise that children who were exposed to a DHA-rich environment during the second half of gestation will have higher IQ scores at 7 years of age than children whose mothers consumed a regular Australian diet typically low in DHA.

\section{METHODS AND ANALYSIS}

\section{Study design}

This is a prospective, follow-up study of children born to women who participated in the DOMInO trial. Children will be invited to undergo a cognitive assessment with a psychologist when they are 7 years $( \pm 3$ months) of age (corrected age for preterm birth). Families could request to be unblinded after completion of analysis of the 18-month results. Families who requested unblinding were given the telephone number of an independent statistician who held the randomisation sequence, and were asked not to discuss treatment allocation with study staff. All families, clinicians and study staff are blinded to group treatment allocation, with the exception of families who requested unblinding prior to the follow-up. At the time of the 4-year follow-up, $2 \%$ of treatment group families and $5 \%$ of control group families had requested to be unblinded, and this knowledge did not appear to influence child DHA intake from food or supplements.

\section{Setting}

Children in the neurodevelopment cohort were born at the Women's and Children's Hospital, or the Flinders Medical Centre, Adelaide, Australia. Appointments will be conducted in study clinics at the hospital and medical centre, where possible. If necessary, appointments will be conducted at the participant's home, or at a location close to their home such as a school or community centre. Appointments will start March 2013 and will be completed by August 2015.

\section{Participants and recruitment}

All children included in the DOMInO trial neurodevelopment cohort, who have not died and whose parents have not withdrawn consent, will be invited to participate in the 7-year follow-up $(n=638,88.2 \%$ of the original $n=726$ ). Primary carers for eligible children will be initially contacted via an invitation letter sent 3 months prior to the child's seventh birthday, followed by a telephone call. Figure 1 is a flow chart of the neurodevelopment cohort follow-up assessments according to the CONSORT statement.

\section{Measures}

See table 1 for a summary of all outcomes assessed and measures used. The majority of the measures used will be psychologist administered, with the addition of some parent-completed questionnaires. The assessors for the follow-up study will be specifically trained and supervised by a supervising psychologist to ensure standardisation between assessors. All assessors will need to correctly administer an assessment on a non-study participant for approval by the supervising psychologist prior to conducting study appointments. The supervising psychologist will audit the first 20 assessments completed by each assessor, and if standardisation is assured, every fourth assessment by each assessor will be audited.

Primary outcome: Full-scale IQ at 7 years of age will be assessed using the Wechsler Abbreviated Scale of Intelligence, Second Edition (WASI-II). ${ }^{46}$ The WASI-II consists of four subtests (block design, vocabulary, matrix reasoning and similarities) and provides a brief (average $30 \mathrm{~min}$ ) and reliable estimate of the child's general intellectual functioning. Full-scale IQ Verbal Comprehension Index and Perceptual Reasoning Index scores will be calculated. Each scale is age standardised with a mean of 100 (SD 15). Mild intellectual impairment will be defined as a full-scale IQ from 70 to 84 (from -2 to $<-1$ SD from the mean), and major intellectual impairment defined as an $\mathrm{IQ}<70$ (ie, $<-2$ SD from the mean). Corrected age will be used to standardise the scores of children who were born preterm.

Secondary outcomes: Secondary outcomes include neurobehavioural domains that are thought to be sensitive to DHA depletion and are important indicators of child development: executive function, attention, memory and learning and behaviour.

1. Executive function will be assessed with the Rey Complex Figure (RCF), ${ }^{47}$ the Fruit Stroop test (F-Stroop),${ }^{48}$ the Number Repetition Subtest of the CELF, 4th Edition (CELF-4) ${ }^{49}$ and the BRIEF. ${ }^{50}$ The RCF requires participants to copy a complex geometric figure and evaluates spatial organisation (the ability to perceive and interpret complex spatial stimuli) and strategic decision-making (the capacity to plan ahead and devise efficient and effective strategies to reach a specific goal). The F-Stroop assesses behavioural inhibition and mental flexibility. The Number Repetition from the CELF-4 requires participants to recall a series of digits in the order they were presented, and in the reversed order. It measures working memory, a core element of executive functioning. The BRIEF is a parent-completed questionnaire that is an important adjunct to formal assessment of executive functioning as some elements of executive dysfunction are more obvious in everyday settings such as the home and kindergarten.

2. Attention will be assessed using subtests from the Test of Everyday Attention for Children (TEACh). ${ }^{51}$ The TEACh provides a comprehensive assessment of attention skills across different modalities. The subtests to be administered will be Sky Search (selective attention), Score! (sustained attention), Creature Counting (attentional control) and Sky Search Dual Task (divided attention). The divided attention score will be calculated by multiplying the proportion of 


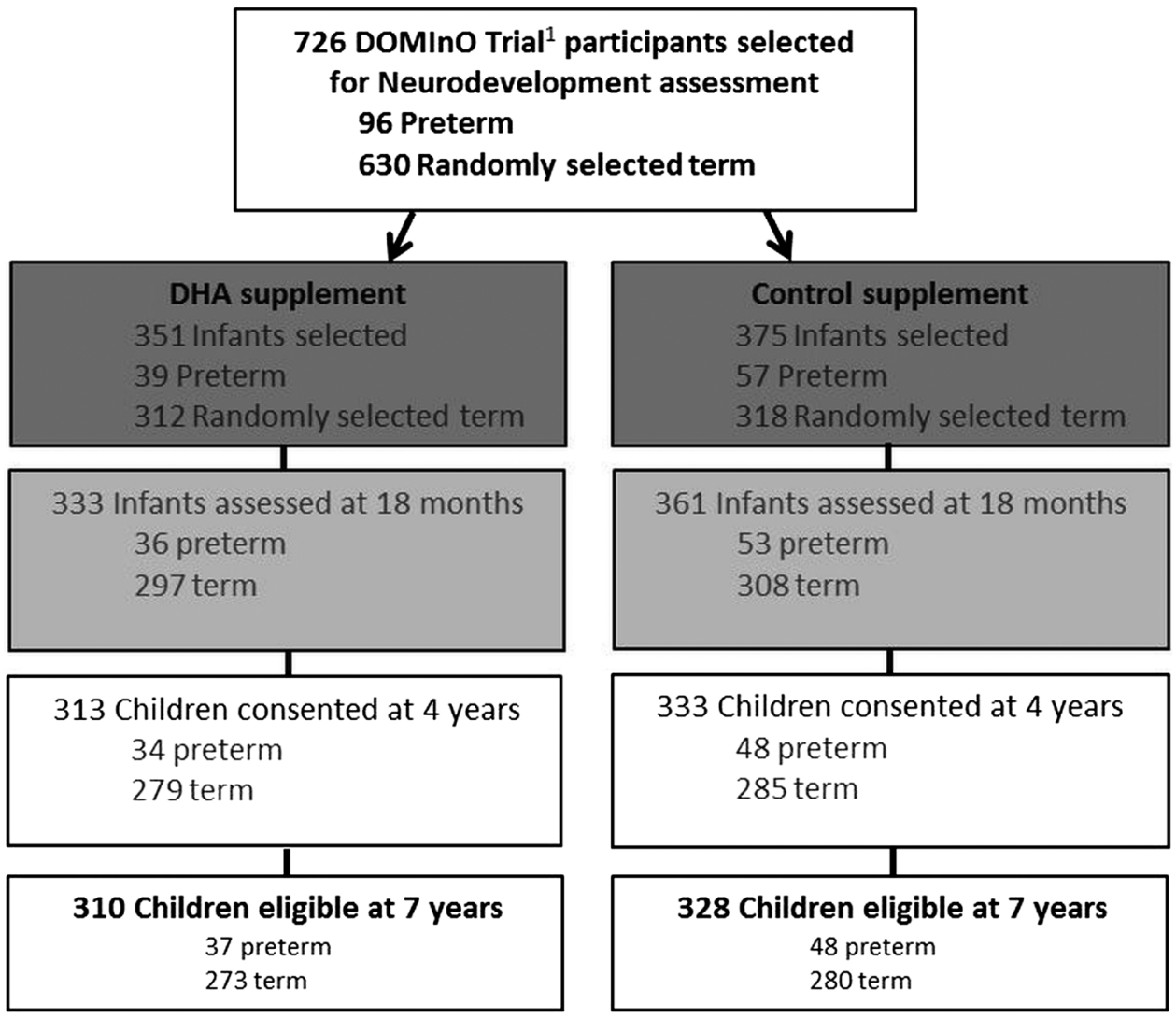

Figure 1 Flow chart of participants selected for neurodevelopment follow-up assessment in the DOMInO trial.

${ }^{1}$ Docosahexaenoic acid to Optimise Mother Infant Outcome Trial. DHA, docosahexaenoic acid.

visual stimuli found by the proportion of auditory stimuli counted, multiplied by 10 (with 10 signifying a perfect score). ${ }^{52}$

3. Memory and learning will be assessed with the Rey Auditory Verbal Learning Test (RAVLT). ${ }^{53}$ This test is used extensively to assess immediate verbal memory, learning ability and delayed recall. It requires the child to learn a list of 15 spoken words over five trials. Delayed recall and recognition trials will also be administered.

4. Language will be measured with the core subtests of the CELF-4. ${ }^{49}$ This test will provide a Core Language Score with a mean of 100 and SD of 15 as a measure of general language abilities.

5. Behaviour will be evaluated with the parent version of the Strength and Difficulties Questionnaire (SDQ). The SDQ is a well-validated questionnaire that assesses overall behaviour problems, emotional symptoms, hyperactivity/inattention, peer relationship problems and prosocial behaviour. As there is growing speculation that DHA plays a role in preventing and reducing $\mathrm{ADHD}$, we will also administer a specific ADHD diagnostic questionnaire, namely the Conners' ADHD/Diagnostic and Statistical Manual of Mental Disorders, Fourth Edition (DSM-IV) scales, which will be completed by parents. ${ }^{54}$

6. Academic abilities/educational progress will be captured with the Word Reading, Spelling and Math
Computation subtests of the Wide Range Achievement Test, Fourth edition (WRAT-4). ${ }^{55}$

Other outcomes: Children will have their head, waist and hip circumferences measured, they will be weighed and their height will be measured at the time of the cognitive assessment as an index of the nutritional well-being of children.

Additional data: Sociodemographic data (such as parental age, education, employment, gestational age at birth, birth weight, birth order and sex) were collected for the DOMInO trial at trial entry or at birth. Parental education and employment were collected again at the 4-year follow-up and will also be collected at the 7-year follow-up, as these details may change over time. Information regarding duration of exclusive breast feeding, type of infant formula used, age at introduction to solid foods and the number of, and reason for, hospitalisations have all been collected as part of the DOMInO trial. At the 7-year follow-up, we will again seek information about the child's medically diagnosed conditions (such as autism spectrum disorder or ADHD), medications and hospitalisations. All hospital admissions $>24 \mathrm{~h}$ will be documented as possible adverse events and the frequency of events will be compared between the treatment and control groups. Admission to intensive (level 3) care or death will be treated as possible serious adverse events. The recent use of DHA supplements and DHA-rich or fortified foods were collected 
Table 1 Assessments used at 7 years of age to capture child development

\begin{tabular}{|c|c|c|}
\hline Domains & Measure & Respondent \\
\hline $\begin{array}{l}\text { General } \\
\text { intellectual } \\
\text { ability }\end{array}$ & $\begin{array}{l}\text { Wechsler Abbreviated } \\
\text { Scale of Intelligence, } \\
\text { Second Edition }\end{array}$ & Child \\
\hline $\begin{array}{l}\text { Executive } \\
\text { function }\end{array}$ & Rey Complex Figure & Child \\
\hline $\begin{array}{l}\text { Executive } \\
\text { function }\end{array}$ & Fruit Stroop Task & Child \\
\hline $\begin{array}{l}\text { Executive } \\
\text { function }\end{array}$ & $\begin{array}{l}\text { Number Repetition from } \\
\text { the Clinical Evaluation of } \\
\text { Language } \\
\text { Fundamentals, Fourth } \\
\text { Edition }\end{array}$ & Child \\
\hline $\begin{array}{l}\text { Executive } \\
\text { function }\end{array}$ & $\begin{array}{l}\text { Behaviour Rating } \\
\text { Inventory of Executive } \\
\text { Functioning }\end{array}$ & Parent \\
\hline Attention & $\begin{array}{l}\text { Test of Everyday } \\
\text { Attention for Children }\end{array}$ & Child \\
\hline $\begin{array}{l}\text { Memory and } \\
\text { learning }\end{array}$ & $\begin{array}{l}\text { Rey Auditory Verbal } \\
\text { Learning Test }\end{array}$ & Child \\
\hline Language & $\begin{array}{l}\text { Clinical Evaluation of } \\
\text { Language } \\
\text { Fundamentals, Fourth } \\
\text { Edition }\end{array}$ & Child \\
\hline Behaviour & $\begin{array}{l}\text { Strengths and } \\
\text { Difficulties Questionnaire }\end{array}$ & Parent \\
\hline $\begin{array}{l}\text { Behaviour- } \\
\text { ADHD }\end{array}$ & $\begin{array}{l}\text { Conners' ADHD/DSM-IV } \\
\text { scales }\end{array}$ & Parent \\
\hline $\begin{array}{l}\text { Educational } \\
\text { progress }\end{array}$ & $\begin{array}{l}\text { Wide Range } \\
\text { Achievement Test, } \\
\text { Fourth Edition }\end{array}$ & Child \\
\hline Growth & Anthropometry & Child \\
\hline Demographics & Background questions & Parent \\
\hline
\end{tabular}

at 18 months and 4 years of age, and will again be collected at 7 years.

\section{Sample size and statistical analysis}

There were originally 726 children selected for developmental follow-up. If $80 \%$ of the original 726 participate in the 7-year follow-up, we will have at least $89 \%$ power to detect a four-point difference in full-scale IQ (mean 100 , SD 15) between the treatment and control groups $(\alpha=0.05$, two-sided). If $75 \%$, or even $70 \%$, of the original 726 are successfully followed up at age 7 years, the power remains high (at least $87 \%$ and $85 \%$, respectively). To achieve a minimum of $80 \%$ power, we would need to successfully follow-up $61 \%$ of participants (222 per group). Detection of a four-point difference in IQ is realistic and comparable to the magnitude of cognitive benefit found in 8-year-old children whose mothers consumed 2-3 servings of fish/week during pregnancy compared with those who ate $<1$ serving/week ${ }^{9}$ and the findings from one $\mathrm{RCT}^{19}$ Similar sized differences in
DQ and IQ have been observed between iron deficient anaemic and non-anaemic children ${ }^{56}$ and also in children who were exposed to high and low levels of lead from the environment. ${ }^{57}$ In both cases, public health policy was changed as a result; infant cereals were fortified with iron and the lead is now removed from petrol and the environment as much as possible.

All analyses will be performed on an intention-to-treat basis according to the mother's allocation to the treatment or control group. No interim analyses will be conducted for this study, and all analyses will be performed according to the prespecified statistical analysis plan. Analyses will be performed using SAS V.9.3 or later, and Stata Release V.13 or later. No data transformations are planned or expected. Both adjusted and unadjusted analyses will be performed, with the adjusted results used to draw conclusion about the effect of treatment on the outcomes of interest. Results will be presented as differences in means for continuous outcomes, or relative risks for binary outcomes, with 95\% CIs and two-sided $p$ values. Statistical significance will be assessed at the $5 \%$ level, and no adjustment will be made for the number of analyses planned, as a single primary outcome has been prespecified for the study.

Potential confounders: Since recruiting centre and parity were used as stratification variables in the randomisation process, all analyses will be adjusted for centre and parity.

Adjustment will also be made for additional baseline variables that are potential confounders for some outcomes specified a priori; these include smoking during pregnancy, maternal secondary education, maternal further education and infant sex.

Primary outcome: Mean IQ scores will be compared between the treatment groups using a linear regression model.

Secondary outcomes: Will be analysed using linear regression models for continuous (normally distributed) outcomes and $\log$ binomial regression models for binary outcomes.

Secondary analyses: We will test for evidence of effect modification by sex by including a treatment by sex interaction for primary and secondary neurodevelopmental outcomes, as we have previously found differential effects of DHA supplementation on aspects of the neurodevelopment of boys and girls. ${ }^{35} 58$

Missing data: Data collected on participants up to the point of withdrawal will be included in the analysis. Children who are missing scores on psychological assessments because they were untestable for developmental reasons will be reviewed by a psychologist (who is blinded to treatment group) to determine whether the lowest possible score should be assigned. Multiple imputation will be used to create 100 complete data sets for analysis using the fully conditional specification method separately by treatment group.

Analyses will be performed on the raw and imputed data, with conclusions to be drawn based on the results 
of the analyses performed on the imputed data. Imputed data sets will include all children whose primary carer consented to the follow-up study. Sensitivity analyses will be performed using different imputation models and for all 726 children in the originally selected subsample, excluding known deaths.

Accounting for study design: The selection procedure for the neurodevelopmental follow-up was stratified by preterm status, sex, recruiting centre and time period. Sampling weights were calculated for each infant as the inverse of the probability of selection. Infants will be weighted according to these sampling weights and the stratification variables will be specified in all analyses.

\section{Ethics and dissemination}

Approval in writing from the Human Research Ethics Committee at each study site (the Women's and Children's Hospital, Adelaide and Flinders Medical Centre, Adelaide) shall be granted prior to the initiation of the study at that site. This study will be carried out in accordance with the Australian National Statement on Ethical Conduct in Research Involving Humans which builds on the ethical codes of the Declaration of Helsinki and the Principles of International Conference on Harmonisation Good Clinical Practice (as adopted in Australia). Caregivers will be required to provide written informed consent prior to participation in the follow-up study, and will be given a copy of the signed consent form and participant information sheet. Parents will be advised that they are free to decline any aspect of the 7-year follow-up, or withdraw from the study at any time without prejudice.

This is a follow-up study with no active intervention and is considered a low-risk study. The developmental assessments described in this protocol will be conducted by a team of trained assessors supervised by a psychologist. The full suite of assessments will take each child about $2 \frac{1}{2}$ to $3 \mathrm{~h}$, including a break between neurodevelopmental assessments. The assessments do not pose any apparent physical risk to children and are enjoyable for 7-year-old children. Given the short and engaging nature of the tasks, children generally maintain interest and concentration throughout the assessment. If a child becomes upset or uncooperative during the assessment, the child will be given time to recover or parents offered the opportunity to return and complete the assessment on another occasion.

Parents will be given $\$ 50$ to cover travel/parking and childcare expenses of other siblings not attending the appointment.

The results of this follow-up study will be published in peer-reviewed journals and presented at academic conferences. No individual participants will be identified or identifiable. All data will be analysed in de-identified form. Data, both paper copies and the electronic database, will be kept (locked and password protected) for 30 years after completion of the study and publication of the results.

\section{DISCUSSION}

Despite the paucity of evidence, recommendations exist internationally to increase DHA intake during pregnancy ${ }^{59-61}$ and the nutritional supplement industry markets prenatal DHA supplements to optimise fetal brain development. This project addresses national ${ }^{61}$ and international ${ }^{62}{ }^{63}$ calls for rigorous scientific evidence regarding benefits of fish oil supplementation during pregnancy for child development from RCTs. Such trials are fundamental to establishing a causal link between DHA exposure during gestation and child development. Our follow-up study can provide robust data regarding the potential long-term effects of supplementing the diets of pregnant women with DHA on cognitive functioning in middle childhood. IQ at 7 years is an important outcome as it is known to predict adult IQ academic achievement, income ${ }^{43}$ and employment. ${ }^{43}{ }^{44}$ In fact, a one-point increase in a nation's average IQ is associated with a $0.11 \%$ annual increase in quality of life as assessed by gross domestic product per capita. ${ }^{64}$ If the results of this study indicate beneficial effects of DHA supplementation, changes to public health policy and subsequent strengthening of human capital has the potential for enormous economic benefits for Australia and the World.

Only two other RCTs have followed children through to 7 years of age after supplementing pregnant women with DHA; however, one study only assessed 143 children of the 590 participants included in the trial $(75 \%$ attrition $)^{20}$ and the other study only included 50 of 98 children $(49 \% \text { attrition })^{33}$ which meant the randomisation integrity may not have been maintained in either study.

Strengths of our study include building on a wellpowered, well-conducted multicentre RCT with the highest retention rates to date, and assessment of a range of neurodevelopmental domains. The DOMInO trial has the broadest inclusion criteria of all the RCTs of DHA supplementation in pregnancy to maximise representativeness of the sample.

The DOMInO trial is likely one of the last opportunities to compare the effect of a DHA supplement with a placebo due to the high use of prenatal supplements that contain DHA by pregnant women today. We will provide the first robust data regarding the long-term effects of maternal DHA supplementation during pregnancy.

\section{Author affiliations}

${ }^{1}$ Women's \& Children's Health Research Institute, North Adelaide, South Australia, Australia

${ }^{2}$ South Australian Health and Medical Research Institute, Adelaide, Australia

${ }^{3}$ Victorian Infant Brain Studies (VIBeS), Murdoch Children's Research Institute, Royal Children's Hospital, Parkville, Victoria, Australia

${ }^{4}$ School of Public Health, The University of Adelaide, South Australian Health and Medical Research Institute, Adelaide, Australia

${ }^{5}$ FOODplus Research Centre, School of Agriculture, Food and Wine, Discipline of Paediatrics, The University of Adelaide, Glen Osmond, South Australia, Australia

${ }^{6}$ Neonatal Services, Women's and Children's Hospital, North Adelaide, South Australia, Australia 
Acknowledgements The authors would like to thank all the families that have generously contributed to the DOMInO trial, and the many subsequent follow-up studies. We would like to thank the staff at the Women's and Children's Health Research Institute (Adelaide, Australia) and the Data Management and Analysis Centre (the University of Adelaide, Australia) for contributing to the DOMInO study. Both the original DOMInO trial and the 7-year follow-up study were funded by Australian National Health and Medical Research Grants (DOMIn0 trial: 349301, 7-year follow-up: 1048493). DOMIn0 trial treatment and control capsules were donated by Incromega 500 TG, Croda Chemicals, East Yorkshire, England. MM, RAG and LNY are supported by Australian National Health and Medical Research Fellowships (MM: 1061704, RAG: 1046207, LNY: 1052388).

Contributors MM, LGS, LNY, KT, JFG, PJA, RAG and AJM were involved in study concept and design. JFG and MM were involved in drafting the protocol. JFG, MM, LGS, LNY, KT, PJA, RAG and AJM provided comment and approval of the final draft of the protocol. LNY, MM and LGS provided statistical expertise. MM, LGS, LNY and KT obtained funding. JFG, MM, LGS, LNY, KT, PJA, RAG and AJM provided administrative, technical, or material support.

Funding National Health and Medical Research Council.

Competing interests MM reports serving on scientific advisory boards for Nestle, Fonterra and Nutricia. RAG reports serving on scientific advisory board for Fonterra and Ferrero. Associated honoraria for MM and RAG are paid to their institutions to support conference travel and continuing education for postgraduate students and early career researchers.

Patient consent Obtained.

Ethics approval Women's and Children's Health Network Human Research Ethics Committee.

Provenance and peer review Not commissioned; externally peer reviewed.

Open Access This is an Open Access article distributed in accordance with the Creative Commons Attribution Non Commercial (CC BY-NC 4.0) license, which permits others to distribute, remix, adapt, build upon this work noncommercially, and license their derivative works on different terms, provided the original work is properly cited and the use is non-commercial. See: http:// creativecommons.org/licenses/by-nc/4.0/

\section{REFERENCES}

1. Innis SM. Dietary (n-3) fatty acids and brain development. J Nutr 2007;137:855-9.

2. Haggarty $\mathrm{P}$, Page $\mathrm{K}$, Abramovich DR, et al. Long-chain polyunsaturated fatty acid transport across the perfused human placenta. Placenta 1997;18:635-42.

3. Martinez M. Tissue levels of polyunsaturated fatty acids during early human development. J Pediatr 1992;120(Pt 2):S129-38.

4. Anderson V, Jacobs R, Anderson P. Executive functions and the frontal lobes. A lifespan perspective. New York: Taylor \& Francis, 2008.

5. Anderson P, Doyle LW., Victorian Infant Collaborative Study Group. Neurobehavioral outcomes of school-age children born extremely low birth weight or very preterm in the 1990s. JAMA 2003;289:3264-72.

6. Anderson PJ, Doyle LW., Victorian Infant Collaborative Study Group. Executive functioning in school-aged children who were born very preterm or with extremely low birth weight in the 1990s. Paediatrics 2004;114:50-7.

7. Taylor $\mathrm{GH}$, Hack M, Klein N. Attention deficits in children with $<750$ gm birthweight $<750 \mathrm{gm}$ birthweight. Child Neuropsychol 1998;4:21-34.

8. Bhutta AT, Cleves MA, Casey PH, et al. Cognitive and behavioral outcomes of school-aged children who were born preterm: a meta-analysis. JAMA 2002;288:728-37.

9. Hibbeln JR, Davis JM, Steer C, et al. Maternal seafood consumption in pregnancy and neurodevelopment outcomes in childhood (ALSPAC study): an observational cohort study. Lancet 2007;369:578-285

10. Daniels JL, Longnecker MP, Rowland AS, et al. Fish intake during pregnancy and early cognitive development of offspring. Epidemiology 2004;15:394-402.
11. Oken E, Osterdal ML, Gillman MW, et al. Associations of maternal fish intake during pregnancy and breastfeeding duration with attainment of developmental milestones in early childhood: a study from the Danish National Birth Cohort. Am J Clin Nutr 2008;88:789-96.

12. Oken E, Radesky JS, Wright RO, et al. Maternal fish intake during pregnancy, blood mercury levels, and child cognition at age 3 years in a US cohort. Am J Epidemiol 2008;167:1171-81.

13. Mendez MA, Torrent M, Julvez J, et al. Maternal fish and other seafood intakes during pregnancy and child neurodevelopment at age 4 years. Public Health Nutr 2009;12:1702-10.

14. Gale CR, Robinson SM, Godfrey KM, et al. Oily fish intake during pregnancy-association with lower hyperactivity but not with higher full-scale IQ in offspring. J Child Psychol Psychiatry 2008;49:1061-8.

15. Colombo J, Kannass KN, Shaddy DJ, et al. Maternal DHA and the development of attention in infancy and toddlerhood. Child Dev 2004;75:1254-67.

16. Kannass KN, Colombo J, Carlson SE. Maternal DHA levels and toddler free-play attention. Dev Neuropsychol 2009;34:159-74.

17. Krabbendam L, Bakker E, Hornstra G, et al. Relationship between DHA status at birth and child problem behaviour at 7 years of age. Prostaglandins Leukot Essent Fatty Acids 2007;76:29-34.

18. Lawlor DA, Davey Smith G, Kundu D, et al. Those confounded vitamins: what can we learn from the differences between observational versus randomised trial evidence? Lancet 2004;363:1724-7.

19. Helland IB, Smith L, Saarem K, et al. Maternal supplementation with very-long-chain $n-3$ fatty acids during pregnancy and lactation augments children's IQ at 4 years of age. Pediatrics 2003;111: e39-44.

20. Helland IB, Smith L, Blomén B, et al. Effect of supplementing pregnant and lactating mothers with $n-3$ very-long-chain fatty acids on children's IQ and body mass index at 7 years of age. Pediatrics 2008;122:e472-9.

21. Smuts $\mathrm{CM}$, Huang $\mathrm{M}$, Mundy $\mathrm{D}$, et al. A randomized trial of docosahexaenoic acid supplementation during the third trimester of pregnancy. Obstet Gynecol 2003;101:469-79.

22. Tofail F, Kabir I, Hamadani JD, et al. Supplementation of fish-oil and soy-oil during pregnancy and psychomotor development of infants. $J$ Health Popul Nutr 2006;24:48-56.

23. Judge MP, Harel O, Lammi-Keefe CJ. Maternal consumption of a docosahexaenoic acid-containing functional food during pregnancy: benefit for infant performance on problem-solving but not on recognition memory tasks at age $9 \mathrm{mo}$. Am J Clin Nutr 2007;85:1572-7.

24. Campoy C, Escolano-Margarit MV, Ramos R, et al. Analysis of long term effects of fish oil and 5-MTHF supplementation to pregnant women on neurological outcome of their offspring: the Nuheal trial. J Pediatr Gastroenterol Nutr 2010;50:E23-4

25. Decsi T, Campoy C, Koletzko B. Effect of N-3 polyunsaturated fatty acid supplementation in pregnancy: the Nuheal trial. Adv Exp Med Biol 2005;569:109-13.

26. Dunstan JA, Simmer K, Dixon G, et al. Cognitive assessment of children at 2(1/2) years following fish oil supplementation in pregnancy: a randomized controlled trial. Arch Dis Child Fetal Neonatal Ed 2008;93:F45-50.

27. van Goor SA, Dijck-Brouwer DA, Erwich JJ, et al. The influence of supplemental docosahexaenoic and arachidonic acids during pregnancy and lactation on neurodevelopment at eighteen months. Prostaglandins Leukot Essent Fatty Acids 2011;84:139-46.

28. Carlson SE, Colombo J. KUDOS Trial. Secondary KUDOS Trial. http://clinicaltrials.gov/ct2/show/NCT00266825?term=DHA+and + pregnancy\&rank $=5$

29. Karlsson T, Birberg-Thornberg U, Duchen K, et al. LC-PUFA supplemented to mothers during pregnancy and breast-feeding improves cognitive performance in the children four years later-an rct study. ISSFAL. Maastricht, 2010:113.

30. Ramakrishnan U, Martorell R, Stein AD, et al. Effect of prenatal supplementation with docosahexanoic acid on child size and development at 18 mo: randomized placebo-controlled trial in Mexico. ISSFAL. Maastricht, 2010:112.

31. Mulder KA, King DJ, Innis SM. Omega-3 fatty acid deficiency in infants before birth identified using a randomized trial of maternal DHA supplementation in pregnancy. PLOS ONE 2014;9: e83764.

32. Hurtado JA, Iznaola C, Peña M, et al., NUGELA Group. Effects of maternal $\Omega-3$ supplementation on fatty acids and on visual and cognitive development. J Pediatr Gastroenterol Nutr 2015;61:472-80. 
33. Meldrum S, Dunstan JA, Foster JK, et al. Maternal fish oil supplementation in pregnancy: a 12 year follow-up of a randomised controlled trial. Nutrients 2015;7:2061-7.

34. Gould JF, Smithers LG, Makrides M. The effect of maternal omega-3 (n-3) LCPUFA supplementation during pregnancy on early childhood cognitive and visual development: a systematic review and metaanalysis of randomized controlled trials. Am J Clin Nutr 2013:9:531-44.

35. Makrides M, Gibson RA, McPhee AJ, et al. Effect of DHA supplementation during pregnancy on maternal depression and neurodevelopment of young children: a randomized controlled trial. JAMA 2010;304:1675-83.

36. Gould JF, Makrides M, Colombo J, et al. Randomized controlled trial of maternal omega-3 long-chain PUFA supplementation during pregnancy and early childhood development of attention, working memory, and inhibitory control. Am J Clin Nutr 2014;99:851-9.

37. Makrides M, Gould JF, Gawlik NR, et al. Four-year follow-up of children born to women in a randomized trial of prenatal DHA supplementation. JAMA 2014;311:1802-4.

38. Frankenburg WK, Coons CE. Home Screening Questionnaire: its validity in assessing home environment. J Pediatr 1986;108:624-6.

39. Brugha $\mathrm{T}$, Bebbington $\mathrm{P}$, Tennant $\mathrm{C}$, et al. The list of threatening experiences: a subset of 12 life event categories with considerable long-term contextual threat. Psychol Med 1985;15:189-94.

40. Epstein N, Baldwin L, Bishop D. The McMaster Family Assessment Device. J Marit Fam Ther 1983;9:171-80.

41. Anderson V, Northam E, Hendy J, et al. Developmental neuropsychology - a clinical approach. East Sussex: Psychology Press, 2001.

42. Baron IS. Neuropsychological evaluation of the child. New York: Oxford University Press, 2004.

43. McCall RB. Childhood IQ's as predictors of adult educational and occupational status. Science 1977;197:482-3.

44. Firkowska-Mankiewicz A. Adult careers: does childhood IQ predict later life outcome? JPolicy Practice Intellect Disabil 2011;8:1-9.

45. Jokela M, Batty GD, Deary IJ, et al. Low childhood IQ and early adult mortality: the role of explanatory factors in the 1958 British birth cohort. Pediatrics 2009;124:e380-8.

46. Wechsler D. Wechsler Abbreviated Scale of Intelligence. 2nd edn. PsychCorp; Pearson. USA: Pearson, 2011.

47. Rey A. L'examen clinique en psychlolgique dans les cas d'encephalopathic traumatique. Arch of Psychol 1941;28:286-340.

48. Archibald S, Kerns K. Identification and description of new tests of executive functioning in children. Child Neuropsychol 1999;115-129:115-29.

49. Semel E, Wiig EH, Secord WA. Clinical Evaluation of Language Fundamentals fourth edition Australia and New Zealand standardised edition. PsychCorp; Pearson. Sydney, Australia: Pearson Clinical and Talent Assessment, 2006.
50. Gioia GA, Isquith PK, Guy SC, et al. Behavior Rating Inventory of Executive Function. FL, USA: Psychological Assessment Resources, 1996.

51. Manly T, Robertson IH, Anderson V, et al. TEA-Ch: the test of everyday attention for children. UK: Thames Valley Test Company Ltd. Bury St Edmunds, 1999.

52. Wilson-Ching M, Molloy CS, Anderson VA, et al. Attention difficulties in a contemporary geographic cohort of adolescents born extremely preterm/extremely low birth weight. J Int Neuropsychol Soc 2013:19:1097-108.

53. Rey A. L'examen clnique en psychologie. Paris: Press Universitaire de France, 1964.

54. Conners CK. Conners $3^{T M} A D H D$ index -parent. Multi-health systems. Toronto, Canada: Multi-Health Systems, 2008.

55. Wilkinson GS, Robertson GJ. Wide range achievement test 4. FL, USA: Psychological Assessment Resources, 2006.

56. Walter T, De Andraca I, Chadud P, et al. Iron deficiency anemia: adverse effects on infant psychomotor development. Paediatrics 1989;84:7-17.

57. Baghurst PA, McMichael AJ, Wigg NR, et al. Environmental exposure to lead and children's intelligence at the age of seven years. The Port Pirie Cohort Study. N Engl J Med 1992;327:1279-84.

58. Makrides M, Gibson RA, McPhee AJ, et al. Neurodevelopmental outcomes of preterm infants fed high-dose docosahexaenoic acid: a randomized controlled trial. JAMA 2009;301:175-82.

59. Food and Agriculture Organization of the United Nations and the World Health Organization. Interim summary of conclusions and dietary recommendations on total fat \& fatty acids. Geneva, 2008:1-14.

60. Brenna JT, Lapillonne A. Background paper on fat and fatty acid requirements during pregnancy and lactation. Ann Nutr Metab 2009;55:97-122.

61. Koletzko B, Cetin I, Brenna JT, et al. Dietary fat intakes for pregnant and lactating women. Br J Nutr 2007;98: 873-7.

62. European Food Safety Authority. Opinion of the Scientific Panel on contaminants in the food chain related to the safety assessment of wild and farmed fish. The EFSA Journal 2005;236:1-118.

63. Royal Australian and New Zealand College of Obstetricians and Gynaecologists. Vitamins and mineral supplementation in pregnancy. College Statement, 2011. http://www.ranzcog.edu.au/ component/content/article/503-college-statements-and-guidelines/cobs/279-vitamins-and-minerals-supplementation-c-obs-25.html (accessed Nov 2013)

64. Jones G, Schneider WJ. Intelligence, human capital and economic growth: a Bayesian averaging of classical estimates approach. J Econ Growth 2006;11:71-93. 